\title{
On the interaction of colicin E3 with the ribosome
}

\author{
Raz Zarivach ${ }^{\mathrm{a}, 1}$, Efrat Ben-Zeev ${ }^{\mathrm{b}, 1}$, Nan Wu ${ }^{\mathrm{c}}$, Tamar Auerbach ${ }^{\mathrm{a}, \mathrm{d}}$, Anat Bashan ${ }^{\mathrm{a}}$, \\ Karen Jakes ${ }^{\mathrm{e}}$, Katherine Dickman ${ }^{\mathrm{c}}$, Alexander Kosmidis ${ }^{\mathrm{c}}$, Frank Schluenzen ${ }^{\mathrm{f}}$, \\ Ada Yonath ${ }^{\mathrm{a}, \mathrm{f}}$, Miriam Eisenstein ${ }^{\mathrm{g}}$, Menachem Shoham ${ }^{\mathrm{c}, *}$ \\ a Weizmann Institute of Science, Department of Structural Biology, Rehovot 76100, Israel \\ ${ }^{\mathrm{b}}$ Weizmann Institute of Science, Department of Biological Chemistry, Rehovot 76100, Israel \\ c Case Western Reserve University, School of Medicine, Department of Biochemistry, Cleveland, OH 44106-4935, USA \\ d FB Biologie, Chemie, Pharmazie, Freie Universität Berlin, Takustrasse 3, 14195 Berlin, Germany \\ e Albert Einstein College of Medicine, Department of Physiology and Biophysics, Bronx, NY 10461, USA \\ ${ }^{\mathrm{f}}$ Max-Planck-Research Unit for Ribosomal Structure, Notkestrasse 85, 22603 Hamburg, Germany \\ g Weizmann Institute of Science, Department of Chemical Services, Rehovot 76100, Israel
}

Received 26 March 2002; accepted 8 July 2002

\begin{abstract}
Colicin E3 is a protein that kills Escherichia coli cells by a process that involves binding to a surface receptor, entering the cell and inactivating its protein biosynthetic machinery. Colicin E3 kills cells by a catalytic mechanism of a specific ribonucleolytic cleavage in $16 \mathrm{~S}$ rRNA at the ribosomal decoding A-site between A1493 and G1494 (E. coli numbering system). The breaking of this single phosphodiester bond results in a complete cessation of protein biosynthesis and cell death. The inactive E517Q mutant of the catalytic domain of colicin E3 binds to $30 \mathrm{~S}$ ribosomal subunits of Thermus thermophilus, as demonstrated by an immunoblotting assay. A model structure of the complex of the ribosomal subunit $30 \mathrm{~S}$ and colicin E3, obtained via docking, explains the role of the catalytic residues, suggests a catalytic mechanism and provides insight into the specificity of the reaction. Furthermore, the model structure suggests that the inhibitory action of bound immunity is due to charge repulsion of this acidic protein by the negatively charged rRNA backbone (C) 2002 Société française de biochimie et biologie moléculaire / Éditions scientifiques et médicales Elsevier SAS. All rights reserved.
\end{abstract}

Keywords: Ribosome; Protein biosynthesis; Bacteriocin; Colicin E3; RNase; Toxin

\section{Introduction}

Colicin E3 (colE3) is a protein antibiotic of Escherichia coli that exerts its lethal function by an enzymatic mechanism. It belongs to the family of $\mathrm{E}$ group nuclease colicins (for a review see [1]). In contrast to the DNase E colicins that cleave the target cell genome in a non-specific manner, colicin E3 acts as a highly specific RNase (for a review on RNase E colicins see [2]).

The mode of action of colicin E3 involves the cleavage of a single phosphodiester bond of E. coli $16 \mathrm{~S}$ ribosomal RNA, which contains more than 1500 nucleotides [3-5]. The cleavage site, between adenine 1493 and guanine 1494

\footnotetext{
* Corresponding author. Tel.: +1-216-368-4665; fax: +1-216-368-8741.

E-mail address: mxs10@po.cwru.edu (M. Shoham).

${ }^{1}$ These persons contributed equally.
}

(E. coli numbering system), is close to the turn of the penultimate helix 44 in the vicinity of the 3 ' end and the interface between the small and large ribosomal subunits, and is at a critical position for the interactions of the A-site tRNA and the mRNA with the ribosome [6]. The same cleavage occurs in vitro, when isolated $70 \mathrm{~S}$ ribosomes are incubated with purified colicin E3 [7,8]. This cleavage results in a complete inactivation of the ribosome leading to the death of the target cell. One of these two nucleotides, A1493, together with A1492 and G530, is actively involved in selecting and binding of cognate tRNA [9]. These three bases undergo conformational changes upon tRNA binding, and flip out so that A1493 interacts with the minor groove of the first codon-anticodon base pair and A1492 and G530 are tightly packed into the second base pair of the codon-anticodon helix. Initiation factor 1 (IF1) binds to the two nucleotides of $16 \mathrm{~S}$ rRNA immediately preceding the colicin 
E3 cleavage site and causes substantial conformational changes on the ribosome required for the onset of protein biosynthesis [10]. Hence, it is likely that the colicin E3 cleavage of $16 \mathrm{~S}$ rRNA cripples the ribosome in such a way that it blocks initiation of protein biosynthesis. However, the molecular details of the interaction between the RNase domain of colicin E3 and the ribosome have not yet been revealed experimentally.

The resistance of the producing organism towards its own colicin E3 is due to the presence of an "immunity protein" (IP) of molecular weight $9.8 \mathrm{kD}$, which forms a tight 1:1 complex with colicin E3 [11]. IP specifically blocks the activity of colicin E3 [12,13]. When isolated under mild conditions, colicin E3 is always found in the complexed form with IP. Free IP is produced in large excess by the cell to protect it from the toxicity of endogenous or exogenous colicin E3 [11].

Although bacterial species other than E. coli are not the natural target of colicin E3, because they lack the necessary outer membrane receptors or translocation proteins, ribosomes from unrelated species, such as Bacillus stearothermophilus and Azotobacter vinelandii are inactivated by colicin E3 in vitro [14]. We show here that an inactive mutant of the RNase domain of colicin E3 binds to $30 \mathrm{~S}$ ribosomal subunits of Thermus thermophilus. It is therefore reasonable to assume that colicin E3 would inactivate T. thermophilus ribosomes. This is the justification for using crystal structures of $T$. thermophilus ribosomal particles as targets for colicin E3 docking. In an attempt to derive a mechanism of the action, we have built a model of the interaction of colicin E3 and 16S rRNA by docking the crystal structure of the RNase domain of colicin E3 [15,16] onto the crystal structure of the $30 \mathrm{~S}$ ribosomal subunit [17-19] in silico. This model suggests a catalytic mechanism for the A1493-G1494 cleavage and explains the results of site-specific mutagenesis of active site residues. It also suggests that the inhibitory action of bound IP is due to charge repulsion and not to steric hindrance.

\section{Materials and methods}

\subsection{Preparation of the E517Q mutant of the colicin E3 RNase domain (CE3_455to551_E517Q)}

The E517Q mutant of colicin E3 was prepared as described previously [15]. The C-terminal colicin E3 residues 455-551, containing the E517Q mutation (CE3_455to551_E517Q), were cloned by PCR into the Novagen vector pET15-b between the XhoI and BamHI sites. This construct, named pKSJ187, corresponds to a $13453 \mathrm{Da}$ protein of sequence

MGSSHHHHHHSSGLVPRGSHMLEKGFKDYGHDYHPA PKTENIKGLGDLKPGIPKTPKQNGGGKRKRWTGDKG RKIYEWDSQHGELQGYRASDGQHLGSFDPKTGNQL

KGPDPKRNIKKYL. The N-terminal residues, including the hexa-histidine tag, from the pET15-b vector are shown in italics. The mutated Q517 is underlined. A $48 \mathrm{ml}$ overnight culture of pKSJ187 in the expression strain C41(DE3) [20] was grown in LB/Amp $(100 \mu \mathrm{g} / \mathrm{ml})$ and used to inoculate $4.8 \mathrm{~L} \mathrm{LB} / \mathrm{Amp}$ media. The cells were grown at $37^{\circ} \mathrm{C}$ to a density of $\mathrm{OD}_{600}=0.6$. At this point, $1 \mathrm{mM} \mathrm{IPTG}$ was added to induce the expression of the target protein for $2 \mathrm{~h}$ at $37^{\circ} \mathrm{C}$. Cells were harvested by centrifugation at $6000 \mathrm{rpm}$ at $4{ }^{\circ} \mathrm{C}$ and stored at $-80^{\circ} \mathrm{C}$. The cell pellet was resuspended in $100 \mathrm{ml}$ column buffer $(20 \mathrm{mM}$ Tris- $\mathrm{HCl}, \mathrm{pH}$ 7.9, $0.5 \mathrm{M} \mathrm{NaCl}, 5 \mathrm{mM}$ imidazole). The cells were broken by sonication on ice. Cell debris was removed by centrifugation at $39,000 \mathrm{~g}$ for $25 \mathrm{~min}$ at $4{ }^{\circ} \mathrm{C}$. The supernatant was filtered through a $0.45 \mu \mathrm{m}$ filter. The protein was purified by cobalt affinity chromatography (TALON) of the histidine tag. The filtered cell supernatant was mixed with $15 \mathrm{ml}$ cobalt resin for $1 \mathrm{~h}$ at $4{ }^{\circ} \mathrm{C}$, and then the resin was poured into a column. The column was washed with $200 \mathrm{ml}$ column buffer and then with $100 \mathrm{ml}$ washing buffer $(20 \mathrm{mM}$ Tris- $\mathrm{HCl}, \mathrm{pH} 7.9,0.5 \mathrm{M} \mathrm{NaCl}, 40 \mathrm{mM}$ imidazole), to remove any weakly bound protein. The protein was eluted from the column with $1 \mathrm{M}$ imidazole in $20 \mathrm{mM}$ Tris- $\mathrm{HCl}$, $\mathrm{pH} 7.9,0.5 \mathrm{M} \mathrm{NaCl}$. The yield was $10 \mathrm{mg}$ protein from 4.81 of culture. The protein was concentrated to $10 \mathrm{mg} / \mathrm{ml}$, and dialyzed against $10 \mathrm{mM}$ HEPES, $\mathrm{pH} 7.5,50 \mathrm{mM} \mathrm{NaCl}$, $0.02 \% \mathrm{NaN}_{3}, 10 \%$ glycerol and stored at $-80{ }^{\circ} \mathrm{C}$.

\subsection{Binding assay to 30 S ribosomal subunits}

Binding of the CE3_455to551_E517Q protein to 30S ribosomal subunits of T.thermophilus (T30S) was monitored by incubation of a 3.5 molar excess of the protein over ribosomal subunits at $37{ }^{\circ} \mathrm{C}$ for $30 \mathrm{~min}$ in T30S crystallization buffer ( $1 \mathrm{nM}$ T30S in $10 \mathrm{mM}$ HEPES, $\mathrm{pH} 7.8,10 \mathrm{mM}$ $\mathrm{MgCl}_{2}, 60 \mathrm{mM} \mathrm{NH} \mathrm{N}_{4} \mathrm{Cl}, 0.1 \mathrm{mM}$ DTT). The goal of the experiment was to demonstrate binding at conditions conducive to crystal formation of T30S particles; i.e. in the presence of the crystallization reagent methyl-pentane diol (MPD). In order for the reactants to remain in solution, conditions were selected on the approach towards crystallization of the ribosomal subunits by stepwise addition of MPD. The MPD concentration was increased by $1 \%$ every $20 \mathrm{~min}$ to avoid any precipitation. When the final concentration of MPD reached $15 \%$, the complexes were incubated for $24 \mathrm{~h}$ at $20^{\circ} \mathrm{C}$. Unbound CE3_455to551_E517Q protein was separated from the complex on a Sephadex S-200 column $(0.5 \times 20 \mathrm{~cm})$. The T30S peak was collected and the RNA was stripped off the complex by acetic acid treatment (100 mM MgCl $2,67 \%$ (v/v) glacial acetic acid, stirred for $3 \mathrm{~h}$, centrifuged at $12,000 \mathrm{rpm}$ for $30 \mathrm{~min}$, dialyzed against $2 \%$ acetic acid and lyophilized overnight). The dried proteins were dissolved in $20 \mu \mathrm{l}$ SDS-PAGE sample buffer, divided into two parts and applied on 12\% SDS-PAGE. One gel was dyed with Coomassie Blue $\mathrm{G}$ and the other was blotted onto a nitrocellulose membrane. ColE3 was detected by immunoblotting using mouse anti-his-tag antibodies 
(Sigma) and enhanced chemiluminescence western blotting detection reagents (Amersham Pharmacia Biotech).

\subsection{Site-specific mutagenesis}

Mutagenesis was carried out as described previously [15]. Stratagene's QuikChange Site-Directed Mutagenesis Kit was used to create two separate mutations, H526A and D542A. The presence of each mutation was confirmed by DNA sequencing. ColE3 was expressed from plasmids in C41 (DE3) cells [20]. Ten-ml cultures were grown in fortified broth [21] to mid-log phase and induced with mitomycin $\mathrm{C}(0.5 \mu \mathrm{g} / \mathrm{ml})$ for $3 \mathrm{~h}$. Cells were harvested, resuspended in $1 \mathrm{ml}$ TM buffer (50 mM Tris- $\mathrm{HCl}, \mathrm{pH} 7.6$, $30 \mathrm{mM}$ ammonium chloride, $10 \mathrm{mM}$ magnesium acetate), and broken by sonication. Particulate material was removed by centrifugation and 10-fold dilutions of the supernatant were spot-tested on lawns of sensitive indicator E. coli.

\subsection{Molecular docking}

The model structure of the complex between subunit $30 \mathrm{~S}$ of the ribosome and colicin E3 was obtained by docking. We used the program MolFit [22], which projects each molecule onto a 3D grid and calculates a correlation function between the two grid-representations. MolFit treats the molecules as rigid bodies. It performs a full rotation/translation scan providing an estimate of the degree of surface complementarity (score) for each relative position. Charge complementarity is not taken into account by the algorithm. We used a modified version of MolFit in which contacts involving residues A1493 and G1494 were given extra weight (details of the algorithm will be published elsewhere).

The structure of the colicin E3 C domain, residues 465-551, taken from entry 1e44 in the PDB [16], was docked to three structures of the $30 \mathrm{~S}$ subunit: native T. thermophilus 30S [19] (PDB code 1i94), the 30S subunit from the complex 30S:paromomycin [28] (PDB code 1fjg) and the 30S subunit from the complex 30S:IF1 [10] (PDB code 1hr0). ColE3 residues 455-464 were excluded from the docking calculations because they are not part of the six-stranded antiparallel $\beta$-sheet that makes up the bulk of the $\mathrm{C}$ domain. This $\mathrm{N}$-terminal stretch does not contain any active site residues. Since this stretch makes no contact with the rest of the colicin E3 molecule, it may well function as a linker to the preceding $\mathrm{R}$ domain. Upon completion of the docking process, these residues $455-465$ were added to the model by superposition of the corresponding parts from the crystal structure (pdb code 1e44 [16]). All the water molecules were omitted, as well as the magnesium ions, the tungsten cluster and the terminal regions that bind the tungsten cluster (residues S2:2-38, 226-250, S18:7-21) in native $30 \mathrm{~S}$. Each molecule was projected onto a $250 \times 250 \times 250$ grid, employing a grid interval of 1.277-1.302 $\AA$, depending on the specific structure of the
30S subunit. The angular interval in each scan was $12^{\circ}$, resulting in 8760 relative orientations [23] and for each orientation we kept only one best solution. The 8760 solutions in each scan were sorted by their weighted complementarity scores. The chosen orientation was slightly adjusted manually in order to bring the active site residues within hydrogen bonding distance of the scissile phosphodiester bond. The coordinates were subsequently subjected to conjugate gradient energy minimization in program CNS [24] with T30S coordinates kept fixed.

Figures were prepared with programs RIBBONS [25], MOLSCRIPT [26] and RASTER3D [27].

\section{Results and discussion}

\subsection{Binding of the CE3_455to551_E517Q protein to 30S ribosomal subunits of $T$. thermophilus}

The CE3_455to551_E517Q protein binds to 30S ribosomal subunits of T. thermophilus (T30S), as shown by immunoblotting of the $\mathrm{His}_{6}$-tagged protein with anti-His 6 antibodies (Fig. 1). In order to check for binding under the crystallization conditions of T30S, increasing concentrations of MPD were added to the reaction mixture. As can be seen in Fig. 1B, the CE3_455to551_E517Q protein binds to T30S even at $15 \%$ MPD.

\subsection{Docking of colicin E3 onto 30 S ribosomal subunits}

The top ranking docking solutions from the three docking tests against the T30S subunit were viewed and analyzed. The second highest solution in the docking of colicin E3 against native T30S places the active site residues of the RNase molecule next to A1493 and G1494. A very similar solution is ranked third when colicin E3 is docked against the 30S subunit from the complex 30S:paromomycin [28]. However, such an orientation was not found among the top ranking solutions when colicin E3 was docked against the 30 S subunit from the 30S:IF1 complex, where a different conformation of the bases of A1493 and G1494 is observed [10]. Notably, the extra weight given to residues A1493 and G1494 (see Section 2) prefers docking solutions in which colE3 resides near these residues. However, none of the colicin E3 residues was given extra weight, hence its orientation relative to the $30 \mathrm{~S}$ subunit was unconstrained.

Fig. 2 depicts the model structure of the 30S:colE3 complex formed when colE3 is docked to native T30S, where the conformation of A1493 and G1494 allows colE3 binding without clashes. Colicin E3 occupies the position of the A-site tRNA. The active site of colE3 wraps around the upper part of helix H44, as described below.

The recognition between T30S and colE3 is facilitated by interactions of several colE3 loops with several 30S rRNA domains and with protein S12. Loops 471-480 and 500-505 of colE3 interact with the $30 \mathrm{~S}$ head $(\mathrm{H} 34, \mathrm{H} 30, \mathrm{H} 31$ of the 


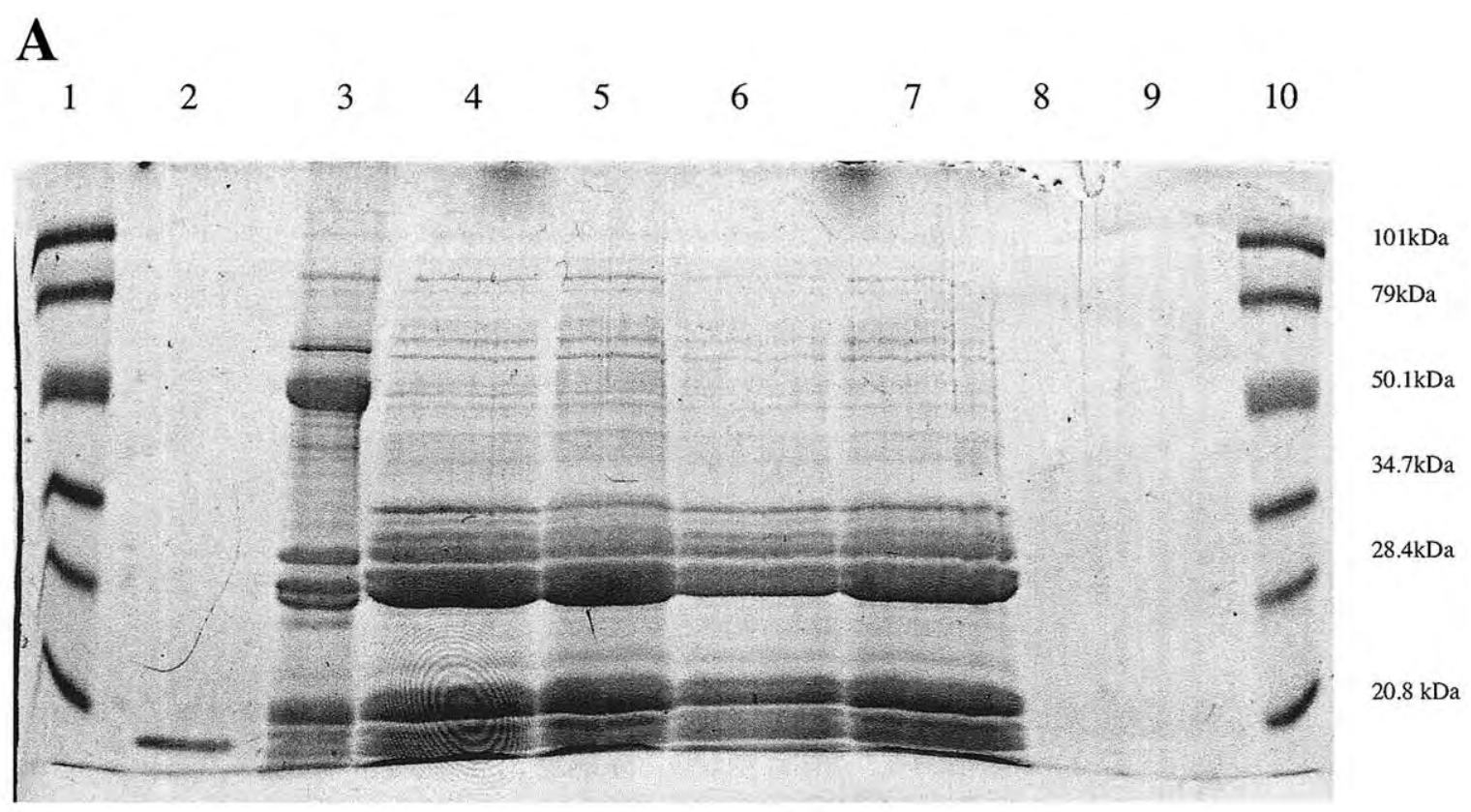

B

$\begin{array}{llllllllll}1 & 2 & 3 & 4 & 5 & 6 & 7 & 8 & 9 & 10\end{array}$

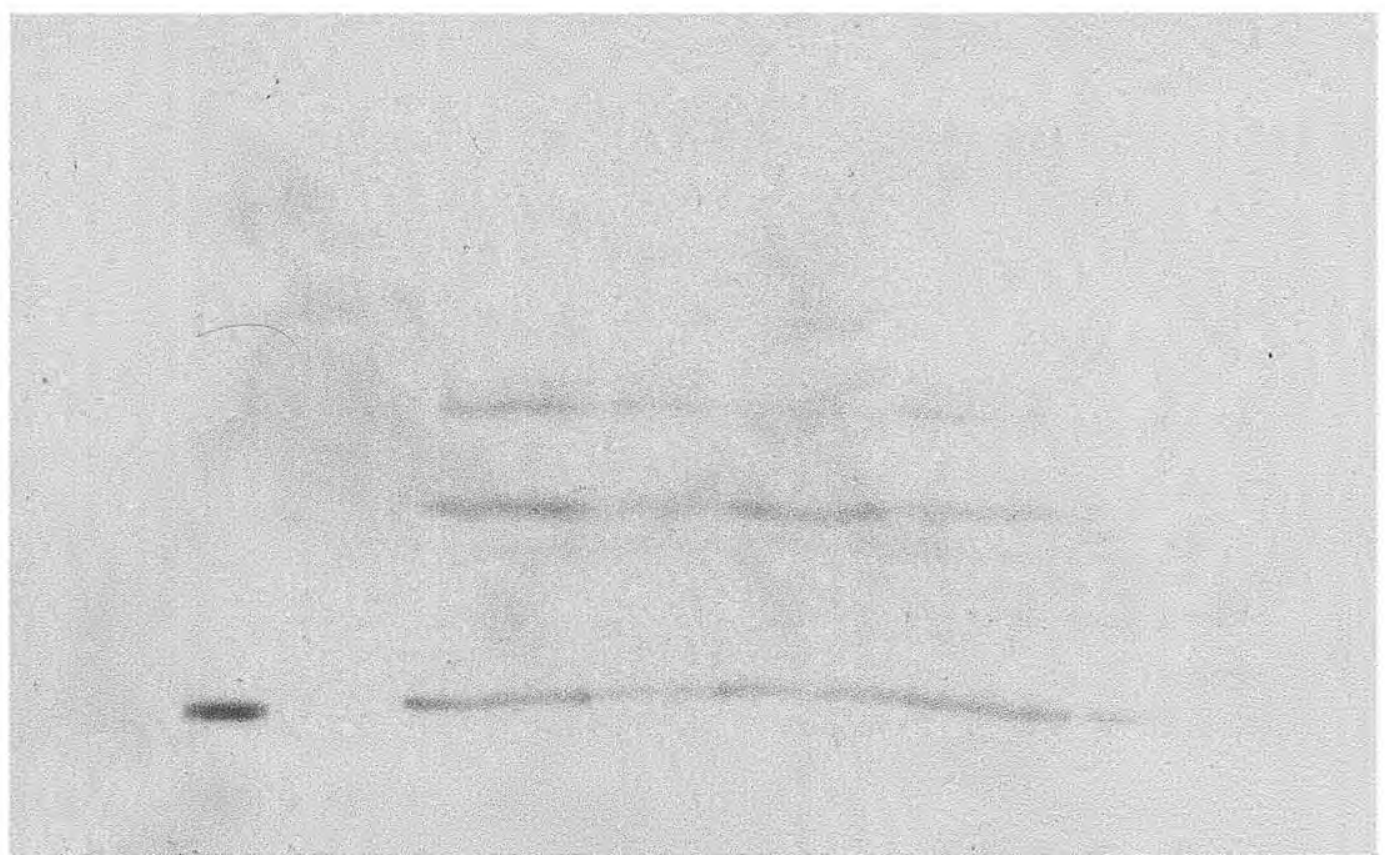

Fig. 1. (A) 12\% SDS-PAGE stained with Coomassie Blue. The lanes are as follows: 1 and 10, molecular weight markers; 2, colE3_455to551_E517Q protein $(2.5 \mu \mathrm{g}) ; 3$, T30S protein extract; 4, T30S protein extract + colE3_455to551_E517Q protein; 5, T30S protein extract + colE3_455to551_E517Q protein + $1 \mathrm{mM} \beta$-mercaptoethanol; 6, T30S protein extract + colE3_455to551_E517Q protein + $0.1 \mathrm{mM}$ DTT; 7, T30S proteins + colE3_455to551_E517Q protein +1 mM DTT. This figure shows that the addition of the colE3_455to551_E517Q protein alters the protein pattern of T30S. (B) Immunoblotting with mouse anti-His-tag antibodies. The only protein in the system with a His tag is colE3_455to551_E517Q. The lanes are the same as in panel A. This figure demonstrates binding of the colE3_455to551_E517Q protein to T30S. In addition to the colE3_455to551_E517Q band, there are higher molecular weight bands containing the His tag. These may indicate the presence of colE3 complexes that are stable under SDS-PAGE conditions. Non-covalent protein complexes occasionally survive the harsh treatment of SDS-PAGE [35]. 


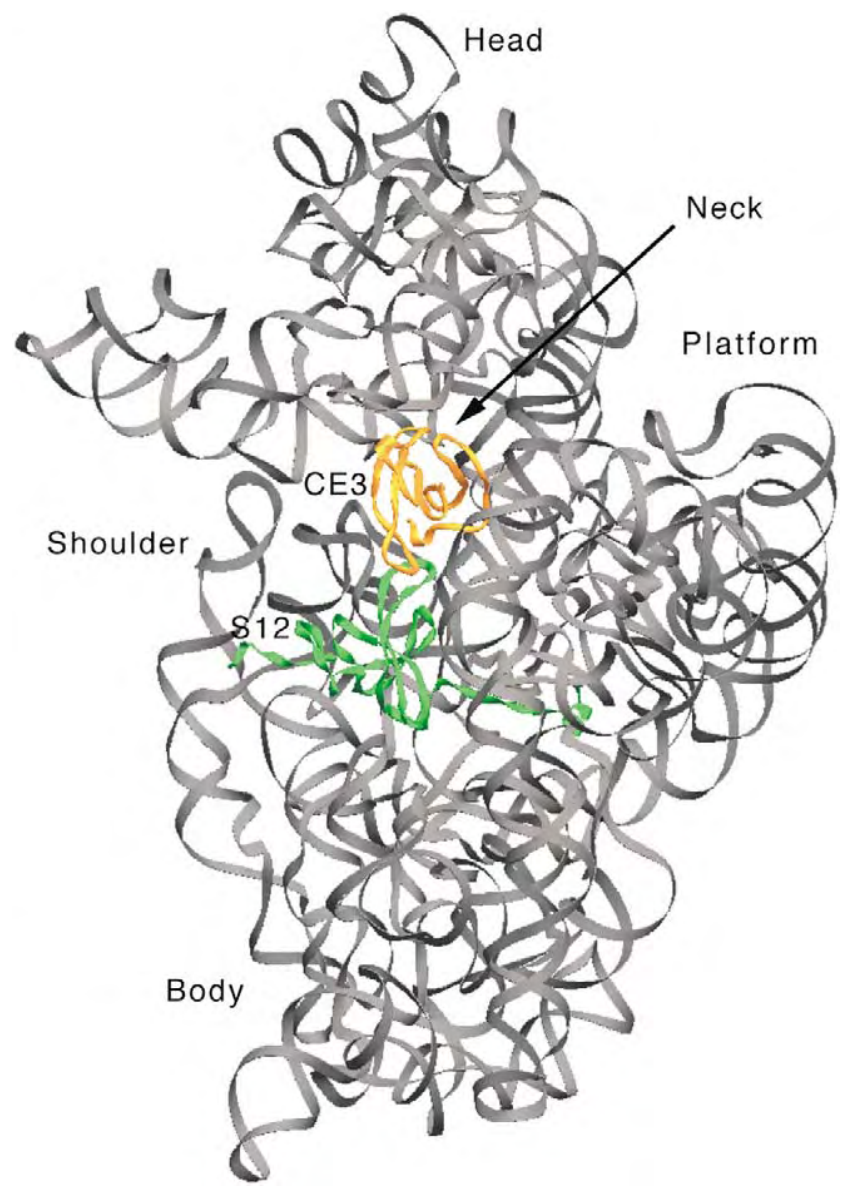

Fig. 2. Docking of the RNase domain of colicin E3 (CE3), shown in yellow, onto the crystal structure of the $16 \mathrm{~S}$ rRNA portion of T. thermophilus 30S ribosomal subunits, shown as gray ribbons [19] (PDB code 1i94), reveals binding to the ribosomal A decoding site located in the neck region of the $30 \mathrm{~S}$ subunit. In addition to numerous contacts with $16 \mathrm{~S}$ rRNA, CE3 also binds to ribosomal proteins, notably S12, shown in green.

rRNA), mostly via electrostatic interactions. For example, Lys 474 and Arg 504 interact with the rRNA backbone O1P atoms of U932 and G1179, respectively. Loops 483-495 and 548-551 of colE3 bridge between H18 in the shoulder of $30 \mathrm{~S}$ and the penultimate helix $\mathrm{H} 44$, which interacts with the 50S subunit in the assembled ribosome. The colE3 loops also make contact with protein S12, which serves as a glue in this region of $30 \mathrm{~S}$ (Fig. 2). The interactions involving loops 483-495 and 548-551 are a mixture of hydrophobic contacts and $\mathrm{H}$-bond interactions at the protein-protein interface and electrostatic interactions with the rRNA backbone (for example, Lys 485, which interacts with G513 of 30S). Loops 520-525 interact with $\mathrm{H} 28$ in the neck region of 30S, mainly with the flip-out nucleotide C1379.

Residues in the active site of colE3 interact with A1493 and G1494 (E. coli numbering) in the upper part of H44 (Fig. 3). Thus, residues Glu517, Asp510, Arg545 and His513 in colE3, which abolish activity when mutated [15], are at interaction distance to the cleavage point between A1493 and G1494.

\subsection{A plausible mechanism for specific $16 S$ rRNA cleavage}

Based upon the docking results, a mechanism presents itself for the specific cleavage of $16 \mathrm{~S}$ rRNA by colicin E3, which is similar to the mechanism proposed for ribonuclease $T_{1}$ by Takahashi and Moore [29]. The catalytic triad consists of Glu517, His513 and Asp510. In the first step, the carboxylate of Glu517 acts as a general base to abstract a proton from the ribose O2'hydroxyl of adenine 1493 (Fig. 4). This leads to a nucleophilic attack of the $\mathrm{O} 2$ ' atom on the phosphate to form a cyclic 2'-3' phosphate that bears a negative charge. The carboxylate of Asp510 activates the imidazole moiety of His513 to stabilize its protonated state. This enables His513 to donate a proton to the leaving 5'-OH RNA fragment upon cleavage. In the second step, His513 acts as a general base to activate a water molecule poised for a nucleophilic attack on the phosphorus atom of the 2'-3' cyclic phosphate. Glu517 acts as a general acid to donate its proton to the O2' oxygen atom. Another residue that has been shown to be important in the catalytic mechanism is Arg545 [15]. The role of Arg545 is to stabilize the pentacoordinated cyclic phosphate intermediate, which bears a negative charge. In order to do so, Arg545 has to adopt a rotamer different from the crystal structures of free colicin E3. This proposed role for Arg545 is in accordance with mutagenesis results, in which the Arg545Ala mutant exhibited diminished activity [15].

Besides His513, there is an additional histidine in the vicinity of the active site, namely His526. Our mutagenesis results indicate that the His526Ala mutant is as active as wild type, so, His526 cannot be involved in catalysis. Likewise, nearby Asp542 is not involved in catalysis, since the Asp542Ala mutant has wild-type activity.

Based upon the crystal structure of recently determined inhibitor complexes of the large-subunit ribotoxic RNase, $\alpha$-sarcin [30], and of a hairpin ribozyme inhibitor complex [31], it was suggested that its cleavage reaction requires flipping of the scissile bond base to align the 2'-hydroxyl groups for nucleophilic in-line attack on the scissile bond. Our results do not indicate a requirement for base flipping to facilitate catalysis, but they also do not provide evidence against it.

\subsection{Inhibition of the RNase activity by the immunity protein}

No information about IP was included in the docking process. To study the inhibitory mechanism of IP, we superimposed the structure of the colE3:IPcomplex onto the colE3 position in the model 30S:colE3 structure. Interest ingly, there are no steric clashes between IP and the 30S subunit in the superposition, a result that could not have been anticipated a priori (Fig. 5). However, we find many negatively charged residues of IP pointing in the direction of the 30S rRNA backbone, resulting in strong electrostatic 

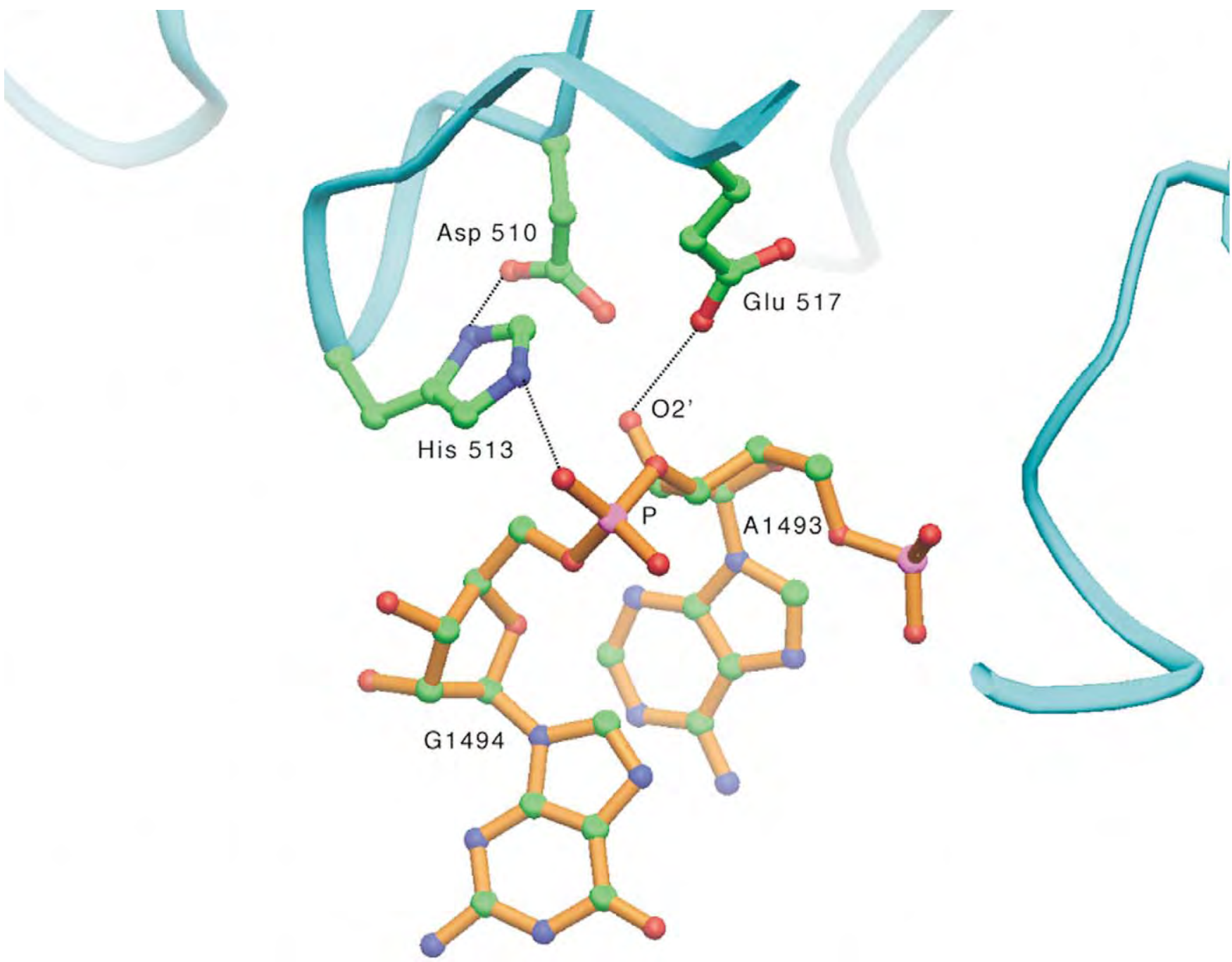

Fig. 3. The interaction of active site residues with the scissile phosphodiester bond linking A1493 and G1494 in 16S rRNA. Atoms within H-bond distance are indicated by broken lines. Glu517 and His513 act as a general base and general acid, respectively. A positive charge on His513 is stabilized by the interaction with Asp510. The cyclic phosphate intermediate is stabilized by an electrostatic interaction with Arg545, not shown here for clarity.

repulsion. For example, Asp67 and Asp70 from the immunity protein point towards the $\mathrm{C} 1191$ and $\mathrm{C} 1190$ phosphate oxygen atoms. Interestingly, some of the negative residues of IP interact with positive residues of colE3 in the IP:colE3 complex (IP:Glu14 with ColE3:Lys485 and IP:Asp49 with ColE3:Lys494), which, according to our model, must be freed in order to interact with 30S. These findings are consistent both with the fact that the immunity protein protects the ribosomes of the producing cell from the colicin they are making and with the idea that the immunity protein must be removed from the colicin at some point before it enters the cytoplasm of the target cell.

\subsection{Interaction with intact $70 S$ particles}

Colicin E3 interacts with intact $70 \mathrm{~S}$ ribosomes and inactivates them both in vivo and in vitro $[7,8]$. The docking of the C domain of colicin E3 onto the crystal structure of T30S was extended to include the large subunit as well. Docked colicin E3 makes no contact with the large subunit.
This observation is in accordance with in vitro studies on the role of $50 \mathrm{~S}$ components in ribosome inactivation by colicin E3 [32]. No individual 50S component was found to affect colicin E3 activity. 50S particles devoid of all but 11 proteins retained their capacity to render ribosomes susceptible to colicin E3 inactivation upon incubation with $30 \mathrm{~S}$ particles at $10 \mathrm{mM} \mathrm{Mg}^{2+}$. The addition of $23 \mathrm{~S}$ rRNA alone did not activate $30 \mathrm{~S}$ particles for inhibition of protein biosynthesis by colicin E3. Association of the 50S with the $30 \mathrm{~S}$ subunit may alter the conformation of helix 44 of $16 \mathrm{~S}$ rRNA, which is in direct contact with the large subunit in the crystal structure of the 70S ribosome [6]. This in turn may poise the scissile phosphodiester bond between A1493 and G1494 for cleavage by colicin E3.

\subsection{Protection from colE3 cleavage by $m R N A$ or $t R N A$}

The position of colE3 in the model structure of the complex 30S:colE3 suggests that mRNA and colE3 binding to the $30 \mathrm{~S}$ subunit are mutually exclusive. Similarly, tRNA 

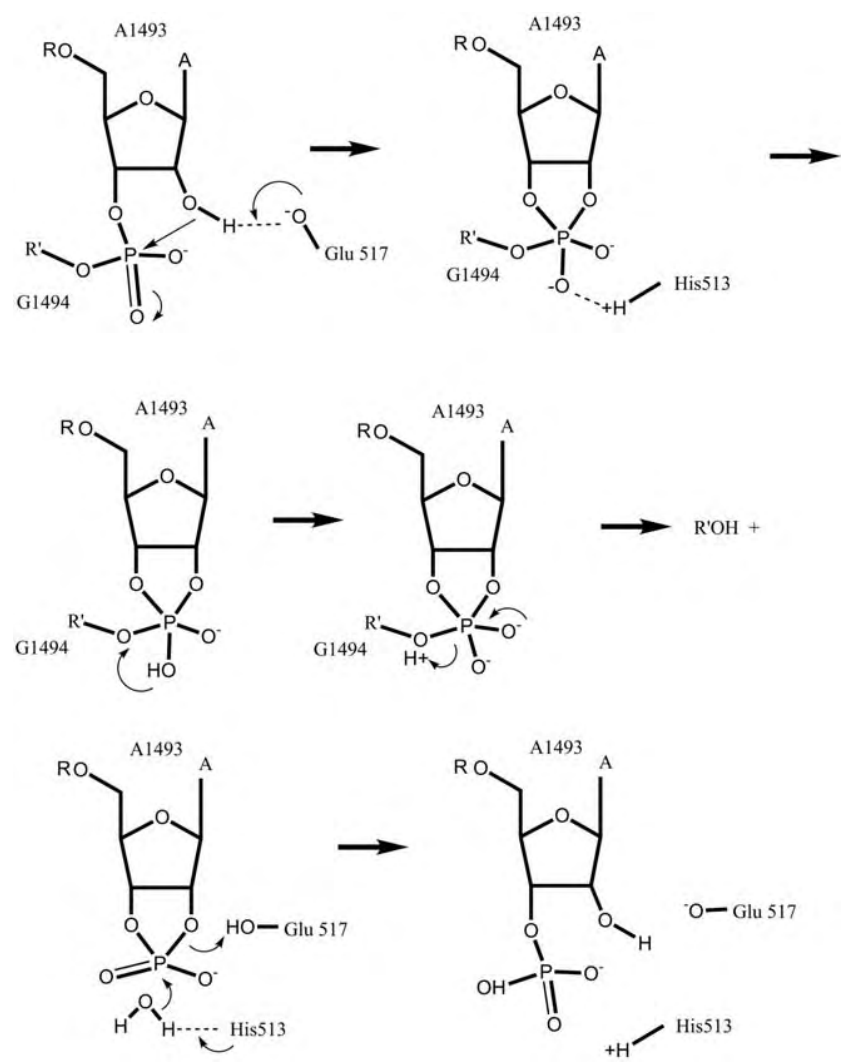

Fig. 4. Schematic representation of the proposed enzymatic mechanism of the ribonuclease activity of colicin E3. R and R' are the RNA chains downstream and upstream of the cleavage site, respectively; A adenine, $G$ guanine.

and colE3 binding are mutually exclusive. These predictions are in agreement with experimental results that mRNA as well tRNA confers protection of ribosomes from colE3 attack $[33,34]$. In contrast, the P-site is free to bind tRNA in the presence of colE3.

\section{Conclusion}

The interaction of colE3 with the ribosome has been established by demonstrating binding of the inactive E517Q colE3 mutant catalytic domain peptide to T30S. Docking of the RNase domain of colE3 onto T30S suggests the colE3 cleavage is confined to a loop of helix 44 on $16 \mathrm{~S}$ rRNA due to shape complementarity. The scissile bond between A1493 and G1494 is poised for cleavage by the action of the catalytic triad Glu517, His513 and Asp510. Additionally, Arg545 stabilizes the negatively charged pentacoordinated phosphorus atom transition state. The inhibitory action of bound immunity protein is due to charge repulsion rather than steric hindrance.
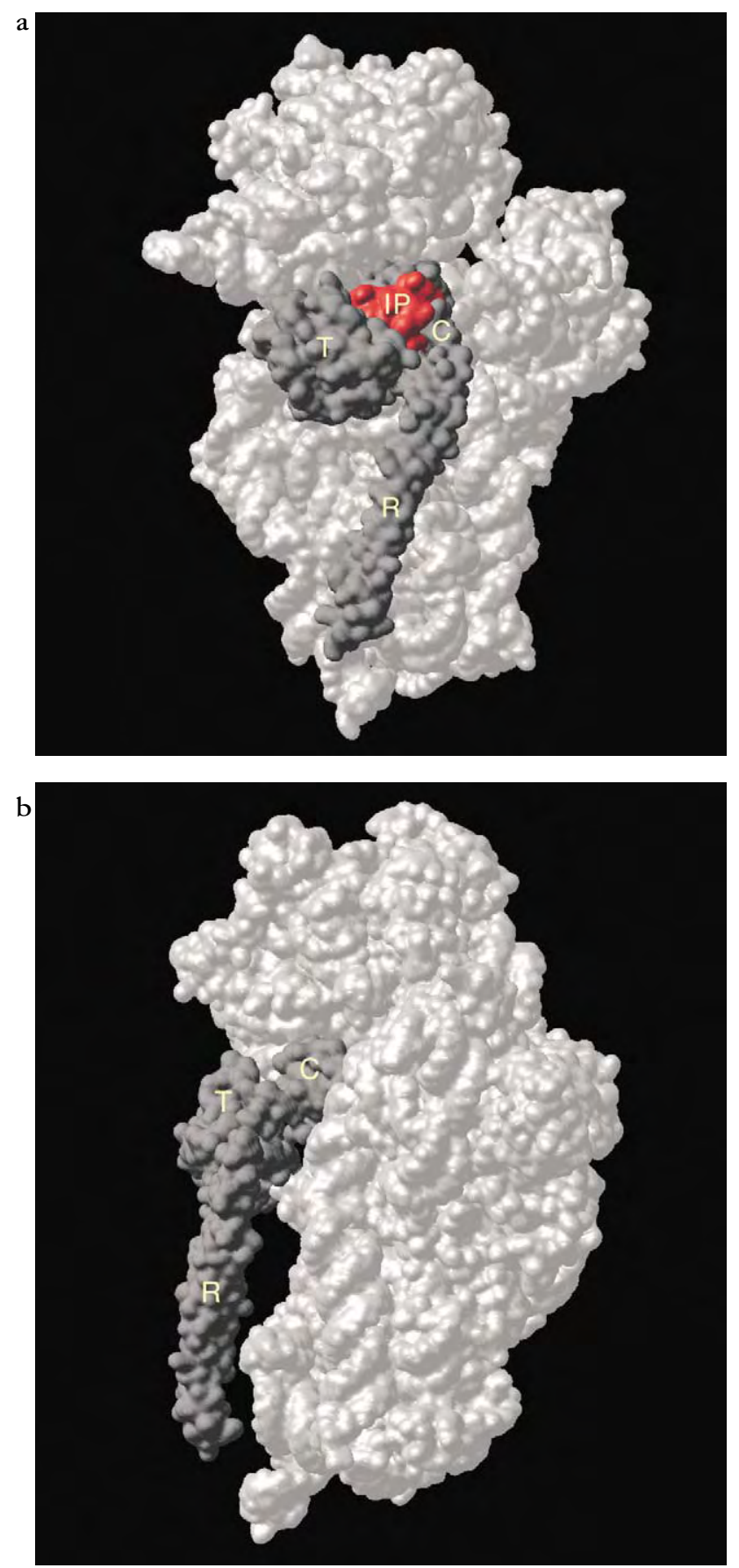

Fig. 5. Surface representation of intact colicin E3 docked onto the 30S ribosomes from $\mathrm{T}$. thermophilus. $\mathrm{C}$ catalytic domain, $\mathrm{T}$ translocation domain, $\mathrm{R}$ receptor-binding domain, IP immunity protein. A, with bound the immunity protein; $\mathrm{B}$, a view rotated by $90^{\circ}$, without the immunity protein. There is no steric hindrance with the ribosome. The presence of the negatively charged immunity protein prevents colicin E3 action on the negatively charged ribosomal RNA due to charge repulsion.

\section{Acknowledgements}

This project was funded by grant MCB97-28420 from the US National Science Foundation (MS), by US National Institutes of Health grant GM34360 (AY) and by US National Institutes of Health grant GM29210 to 
Alan Finkelstein (KJ). We thank all members of the ribosome teams at the Weizmann Institute of Science and at the Max-Planck Research Unit in Hamburg. AY holds the Martin S. Kimmel Professorial Chair at the Weizmann Institute of Science.

\section{References}

[1] Kleanthous, et al., Mode of action of and inactivation of E group nuclease colicins, Biochimie 84 (2002) in press.

[2] H. Masaki, The mode of action, catalytic mechanism and immunity of RNase-type colicins, Biochimie 84 (2002) in press.

[3] C.M. Bowman, J.E. Dahlberg, T. Ikemura, J. Konisky, M. Nomura, Specific inactivation of $16 \mathrm{~S}$ ribosomal RNA induced by colicin E3 in vivo, Proc. Natl. Acad. Sci. USA 68 (1971) 964-968.

[4] B.W. Senior, I.B. Holland, Effect of colicin E3 upon the 30S ribosomal subunit of Escherichia coli, Proc. Natl. Acad. Sci. USA 68 (1971) 959-963.

[5] A.E. Dahlberg, J.E. Dahlberg, Binding of ribosomal protein S1 of Escherichia coli to the $3^{\prime}$ end of 16S rRNA, Proc. Natl. Acad. Sci. USA 72 (1975) 2940-2944.

[6] J.H. Cate, M.M. Yusupov, G.Z.h Yusupova, T.N. Earnest, H.F. Noller, X-ray crystal structures of $70 \mathrm{~S}$ ribosome functional complexes, Science 285 (1999) 2095-2104.

[7] T. Boon, Inactivation of ribosomes in vitro by colicin E3, Proc. Natl. Acad. Sci. USA 68 (1971) 2421-2425.

[8] C.M. Bowman, J. Sidikaro, M. Nomura, Specific inactivation of ribosomes by colicin E3 in vitro and mechanism of immunity in colicinogenic cells, Nature New Biol. 234 (1971) 133-137.

[9] J.M. Ogle, D.E. Brodersen, W.M. Clemons Jr, M.J. Tarry, A.P. Carter, V. Ramakrishnan, Recognition of cognate transfer RNA by the 30S ribosomal subunit, Science 292 (2001) 897-902.

[10] A.P. Carter, W.M. Clemons Jr, D.E. Brodersen, R.J. Morgan-Warren, T. Hartsch, B.T. Wimberly, V. Ramakrishnan, Crystal structure of an initiation factor bound to the 30S ribosomal subunit, Science 291 (2001) 498-501.

[11] K.S. Jakes, N.D. Zinder, Highly purified colicin E3 contains immunity protein, Proc. Natl. Acad. Sci. USA 71 (1974) $3380-3384$.

[12] K. Jakes, N.D. Zinder, T. Boon, Purification and properties of colicin E3 immunity protein, J. Biol. Chem. 249 (1974) 438-444.

[13] J. Sidikaro, M. Nomura, E3-immunity substance: a protein from E3-colicinogenic cells that accounts for their immunity to colicin E3, J. Biol. Chem. 249 (1974) 445-453.

[14] J. Sidikaro, M. Nomura, Colicin E3-induced in vitro inactivation of ribosomes from colicin-insensitive bacterial species, FEBS Lett. 29 (1973) 15-19.

[15] S. Soelaiman, K. Jakes, N. Wu, C. Li, M. Shoham, Crystal structure of colicin E3: implications for cell entry and ribosome inactivation, Mol. Cell 8 (2001) 1053-1062.

[16] S. Carr, D. Walker, R. James, C. Kleanthous, A.M. Hemmings, Inhibition of a ribosome-inactivating ribonuclease: the crystal structure of the cytotoxic domain of colicin E3 in complex with its immunity protein, Structure 8 (2000) 949-960.

[17] F. Schluenzen, A. Tocilj, R. Zarivach, J. Harms, M. Gluehmann, D. Janell, A. Bashan, H. Bartels, I. Agmon, F. Franceschi, A. Yonath, Structure of functionally activated small ribosomal subunit at 3.3 angstroms resolution, Cell 102 (2000) 615-623.
[18] B.T. Wimberly, D.E. Brodersen, W.M. Clemons Jr, R.J. MorganWarren, A.P. Carter, C. Vonrhein, T. Hartsch, V. Ramakrishnan, Structure of the $30 \mathrm{~S}$ ribosomal subunit, Nature 407 (2000) 327-339.

[19] M. Pioletti, F. Schluenzen, J. Harms, R. Zarivach, M. Gluehmann, H. Avila, A. Bashan, H. Bartels, T. Auerbach, C. Jacobi, T. Hartsch, A. Yonath, F. Franceschi, Crystal structures of complexes of small ribosomal subunit with tetracycline, edeine and IF3, EMBO J. 20 (2001) 1829-1839.

[20] B. Miroux, J.E. Walker, Over-production of proteins in Escherichia coli: mutant hosts that allow synthesis of some membrane proteins and globular proteins at high levels, J. Mol. Biol. 260 (1996) 289-298.

[21] P.B. Moses, J.D. Boeke, K. Horiuchi, N.D. Zinder, Restructuring the bacteriophage f1 genome: expression of gene VIII in the intergenic space, Virology 104 (1980) 267-278.

[22] E. Katchalski-Katzir, I. Shariv, M. Eisenstein, A.A. Friesem, C. Aflalo, I.A. Vakser, Molecular surface recognition: determination of geometric fit between proteins and their ligands by correlation techniques, Proc. Natl. Acad. Sci. USA 89 (1992) 2195-2199.

[23] M. Eisenstein, I. Shariv, G. Koren, A.A. Friesem, E. KatchalskiKatzir, Modeling supra-molecular helices: extension of the molecular surface recognition algorithm and application to the protein coat of the tobacco mosaic virus, J. Mol Biol. 266 (1997) 135-143.

[24] A.T. Brünger, P.D. Adams, G.M. Clore, W.L. DeLano, P. Gros, R.W. Grosse-Kunstleve, J.S. Jiang, J. Kuszewski, M. Nilges, N.S. Pannu, R.J. Read, L.M. Rice, T. Simonson, G.L. Warren, Crystallography and NMR system: a new software suite for macromolecular structure determination, Acta Crystallogr D 54 (1998) 905-921.

[25] M. Carson, Ribbons, Acta Crystallogr B 277 (1997) 493-505.

[26] P.J. Kraulis, MOLSCRIPT: a program to produce both detailed and schematic plots of protein structures, J. Appl. Crystallogr. 24 (1991) 946-950.

[27] E.A. Merritt, D.J. Bacon, Raster3D: photorealistic molecular graphics, Methods Enzymol. 277 (1997) 505-524.

[28] A.P. Carter, W.M. Clemons, D.E. Brodersen, R.J. Morgan-Warren, B.T. Wimberly, V. Ramakrishnan, Functional insights from the structure of the $30 \mathrm{~S}$ ribosomal subunit and its interactions with antibiotics, Nature 407 (2000) 340-348.

[29] K. Takahashi, S. Moore, Ribonuclease $\mathrm{T}_{1}$, in: P.D. Boyer (Ed.), The Enzymes, third ed, 15, Academic Press, New York, 1982, pp. $435-468$.

[30] X. Yang, T. Gérczei, L.T. Glover, C.C. Correll, Crystal structures of restrictocin-inhibitor complexes with implications for RNA recognition and base flipping, Nat. Struct. Biol. 8 (2001) 968-973.

[31] P.B. Rupert, A.R. Ferré-D'Amaré, Crystal structure of a hairpin ribozyme-inhibitor complex with implications for catalysis, Nature 410 (2001) 780-786.

[32] G. Sander, Role of components of the 50S ribosomal subunit in colicin E3 activity, FEBS Lett. 83 (1977) 293-296.

[33] Y. Kaufmann, A. Zamir, Protection of E. coli ribosomes against colicin E3-induced inactivation by bound aminoacyl-tRNA, FEBS Lett. 36 (1973) 277-280.

[34] Y. Kaufmann, A. Zamir, The effect of tRNA derivatives bound with natural or synthetic mRNA on the interaction of Escherichia coli ribosomes with colicin E3, Eur. J. Biochem. 53 (1975) 599-603.

[35] X.Q. Qiu, K.S. Jakes, A. Finkelstein, S.L. Slatin, Site-specific biotinylation of colicin Ia. A probe for protein conformation in the membrane, J. Biol. Chem. 269 (1994) 7483-7488. 